\title{
Structural Control of Schiff Base Ligands for Selective Extraction of Copper(II)
}

\author{
Syunichi Oshima, ${ }^{* 1}$ Naoki Hirayama, ${ }^{* \dagger}$ Koji Kubono, ${ }^{* 3}$ Hisao KoKuSen, ${ }^{* 4}$ \\ and Takaharu HoNJo*2 \\ *1 Division of Basic Sciences, Graduate School of Natural Science and Technology, Kanazawa University, \\ Kanazawa 920-1192, Japan \\ *2 Department of Chemistry, Faculty of Science, Kanazawa University, Kanazawa 920-1192, Japan \\ *3 Division of Natural Science, Osaka Kyoiku University, Kashiwara 582-8582, Japan \\ *4 Department of Environmental Engineering, Kanazawa Institute of Technology, \\ Nonoichi, Ishikawa 921-8501, Japan
}

\begin{abstract}
Structural control of Schiff base ligands for selective extraction of copper(II) was investigated by changing pendant arms and the distance between two imine-N donor atoms in ligands. Di-Schiff base ligands, $N, N^{\prime}$-bis(2-quinolylmethylidene)1,2-diiminoethane (BQIE), $N, N^{\prime}$-bis(2-pyridylmethylidene)-1,3-diimino-2,2-dimethylpropane (BPMP) and $N, N^{\prime}$-bis(2quinolylmethylidene)-1,3-diimino-2,2-dimethylpropane (BQMP), were used as complexation reagents for ion-pair extraction of divalent transition metal cations into nitrobenzene with picrate anion. The pendant arms affected the lipophilicity of ligand to nitrobenzene, due to their polarity. The distance between two imine-N atoms, on the contrary, was a factor of controlling the extraction selectivity. BQMP has both 2-quinolyl pendant arms and trimethylene backbone structure; use of BQMP as a complexation reagent led to the selective extraction of $\mathrm{Cu}^{2+}$ in the system.
\end{abstract}

(Received August 19, 2002; Accepted September 24, 2002)

In ion-pair extractive separation of metal cations using a complexation reagent and a counter anion, use of a higher selective complexation reagent is one of the most important factors to realize their mutual separation. ${ }^{1}$ Therefore, development of new selective complexation reagent and investigations about the effect of steric structure around donor atoms in the reagent on the ion recognition ability (extraction selectivity) are very important for improving the mutual separation. $^{2}$

Earlier, we studied the nature of neutral di-Schiff base ligands having two 2-pyridyl pendant arms, $N, N^{\prime}$-bis(2pyridylmethylidene)-1,2-diiminoethane $(\mathrm{BPIE})^{3-6}$ and its analogues, as complexation reagents for the ion-pair extraction of divalent metal cations into nitrobenzene with picrate anion. ${ }^{7}$ These ligands acted as bidentate ones using two imine-N donor atoms in the extraction system, and 2-pyridyl pendant arms acted mainly to raise the hydrophobicity of the ligand and the extractability of the complexes. Furthermore, it was found that the extraction selectivity and extractability can be controlled by introduction of substituents near the imine- $\mathrm{N}$ donor atoms. In these extraction systems, in addition, relatively high extraction selectivity for $\mathrm{Cu}^{2+}$ was obtained.

In this research, we investigated the effects of pendant arms in the Schiff base ligands and of distance between the two imine-N donor atoms on the extractability and the ion-pair extraction selectivity; BPIE was used as a model compound. Two BPIE analogues, $N, N^{\prime}$-bis(2-quinolylmethylidene)-1,2-diiminoethane (BQIE) having 2-quinolyl groups as pendant arms and $N, N^{\prime}$ -

† To whom correspondence should be addressed.

E-mail: hirayama@cacheibm.s.kanazawa-u.ac.jp bis(2-pyridylmethylidene)-1,3-diimino-2,2-dimethylpropane $(\mathrm{BPMP})^{8}$ (see Fig. 1) having relatively long distance between two imine- $\mathrm{N}$ atoms, were used for the investigation. The pendant arms affected the lipophilicity of ligand to nitrobenzene, whereas the distance between the imine- $\mathrm{N}$ atoms was a factor in controlling the extraction selectivity. Consequently, the relative selectivity of $\mathrm{Cu}^{2+}$ in BPMP-NaPic system was higher than that of BPIE-NaPic system due to the suitable distance for complexation of $\mathrm{Cu}^{2+}$. From these viewpoints, it was found that another BPIE analogue, $N, N^{\prime}$ -
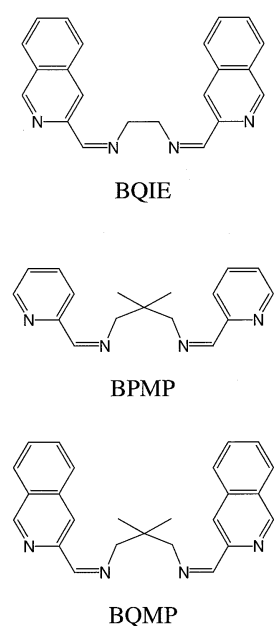

Fig. 1 Chemical structure of BQIE, BPMP and BQMP. 
bis(2-quinolylmethylidene)-1,3-diimino-2,2-dimethylpropane (BQMP) (see Fig. 1), can be used for selective extraction of $\mathrm{Cu}^{2+}$ from other divalent cations.

\section{Experimental}

Apparatus

A Hitachi Model Z-6100 polarized Zeeman atomic absorption spectrophotometer was used for the determination of the concentration of a metal in aqueous solution. A Shimadzu Model UV-160 UV/VIS spectrophotometer with $1.0 \mathrm{~cm}$ quartz cell was used for the measurement of absorption spectra. A Horiba Model F-12 pH meter equipped with a Horiba 9610-10D combined glass electrode was used to determine the $\mathrm{pH}$ values.

\section{Reagents}

BPMP was synthesized as follows: To a 2-propanol solution of 2-pyridinecarboxaldehyde $(6.4 \mathrm{~g}, 0.06 \mathrm{~mol})$ was added slowly 2,2-dimethyl-1,3-propanediamine ( $3.1 \mathrm{~g}, 0.03 \mathrm{~mol})$ in 2propanol. After the mixture was stirred gently for $24 \mathrm{~h}$ and the 2-propanol was removed by rotary evaporation, an orangeyellow residual liquid product was obtained. This was crystallized by rubbing with a glass rod. The yellow product was washed with cold 2-propanol. Yield, 64\%. Anal. Calcd for $\mathrm{C}_{17} \mathrm{H}_{20} \mathrm{~N}_{4}$ : C 72.82, H 7.19, N 19.99. Found: C 72.81, H 7.23, N 19.86. ${ }^{1} \mathrm{H} \mathrm{NMR}\left(\mathrm{CDCl}_{3}\right.$ vs. TMS $): \delta=1.07\left(\mathrm{~s}, 6 \mathrm{H},-\mathrm{CH}_{3}\right), 3.61$ $\left(\mathrm{m}, 4 \mathrm{H},=\mathrm{N}-\mathrm{CH}_{2}-\mathrm{C}-\right), 7.32(\mathrm{~m}, 2 \mathrm{H},-\mathrm{N}=\mathrm{CH}-\mathrm{py}), 7.75(\mathrm{~m}, 2 \mathrm{H}$, py), 8.06 (m, 2H, py), 8.39 ( $\mathrm{m}, 2 \mathrm{H}$, py), 8.63 ( $\mathrm{m}, 2 \mathrm{H}, \mathrm{py})$.

BQIE and BQMP were synthesized as follows: to an ethanolic solution of 2-quinolinecarboxaldehyde $(3.1 \mathrm{~g}, 0.02 \mathrm{~mol})$ was added ethylenediamine $(0.6 \mathrm{~g}, 0.01 \mathrm{~mol})$ or 2,2-dimethyl-1,3propanediamine $(0.7 \mathrm{~g}, 0.01 \mathrm{~mol})$ in ethanolic solution. The mixture was stirred for $1 \mathrm{~h}$, during which a light yellow precipitate formed. The obtained crude product was recrystallized from ethanol and then washed with cold ethanol.

For BQIE: Yield, 62\%. Anal. Calcd for $\mathrm{C}_{22} \mathrm{H}_{18} \mathrm{~N}_{4}$ : C 78.08, $\mathrm{H}$ 5.36, N 16.56. Found: C 78.09, H 5.42, N 16.46. ${ }^{1} \mathrm{H}$ NMR $\left(\mathrm{CDCl}_{3}\right.$ vs. TMS): $\delta=4.17$ (s, $\left.4 \mathrm{H},-\mathrm{CH}_{2} \mathrm{CH}_{2}-\right), 7.56(\mathrm{~m}, 2 \mathrm{H}$, quinoline), $7.72(\mathrm{~m}, 2 \mathrm{H}$, quinoline), $7.80(\mathrm{~m}, 2 \mathrm{H}$, quinoline), $8.16(\mathrm{~m}, 6 \mathrm{H}$, quinoline), $8.62(\mathrm{~m}, 2 \mathrm{H},-\mathrm{N}=\mathrm{CH}-)$.

For BQMP: Yield, 42\%. Anal. Calcd for $\mathrm{C}_{25} \mathrm{H}_{24} \mathrm{~N}_{4}$ : C 78.91, $\mathrm{H}$ 6.36, N 14.73. Found: C 79.04, H 6.45, N 14.67. ${ }^{1} \mathrm{H}$ NMR $\left(\mathrm{CDCl}_{3}\right.$ vs. TMS): $\delta=1.12\left(\mathrm{~s}, 6 \mathrm{H},-\mathrm{CH}_{3}\right), 3.72(\mathrm{~m}, 4 \mathrm{H}$, $\left.=\mathrm{N}-\mathrm{CH}_{2} \mathrm{C}-\right), 7.58$ (m, 2H, quinoline), $7.74(\mathrm{~m}, 2 \mathrm{H}$, quinoline), 7.84 (m, 2H, quinoline), 8.22 (m, $6 \mathrm{H}$, quinoline), 8.59 ( $\mathrm{m}, 2 \mathrm{H}$, $-\mathrm{N}=\mathrm{CH}-$ ).

\section{Acid dissociation and distribution of ligands ${ }^{7}$}

Acid dissociation constants $\left(K_{\mathrm{a} i}\right)$ and nitrobenzene-water distribution constants $\left(K_{\mathrm{D}}\right)$ of the ligands were determined as follows: a $5 \mathrm{~cm}^{3}$ amount of organic phase containing $1 \times 10^{-4}$ mol dm $\mathrm{dm}^{-3}$ of a ligand was equilibrated with a $5 \mathrm{~cm}^{3}$ amount of aqueous phase containing $1 \times 10^{-1} \mathrm{~mol} \mathrm{dm}^{-3}$ of sodium chloride and $1 \times 10^{-2} \mathrm{~mol} \mathrm{dm}^{-3}$ of the buffer [chloroacetic acid, acetic acid or 2-( $N$-morpholino)ethanesulfonic acid (MES)] by shaking for $1 \mathrm{~h}$. After centrifugation, the ligand that remained in the organic phase was recovered as charged species by shaking with $5 \times 10^{-1} \mathrm{~mol} \mathrm{dm}^{-3}$ of sulfuric acid for $1 \mathrm{~h}$. The recovered ligand was determined spectrophotometrically after washing the sulfuric acid phase with $o$-dichlorobenzene for $15 \mathrm{~min}$, and its distribution ratio $\left(D_{\mathrm{L}}\right)$ was calculated. The values of $\mathrm{p} K_{\mathrm{a} i}$ and $\log K_{\mathrm{D}}$ were determined from the $\log D_{\mathrm{L}} v s$. pH plot by using a nonlinear least squares fitting method.
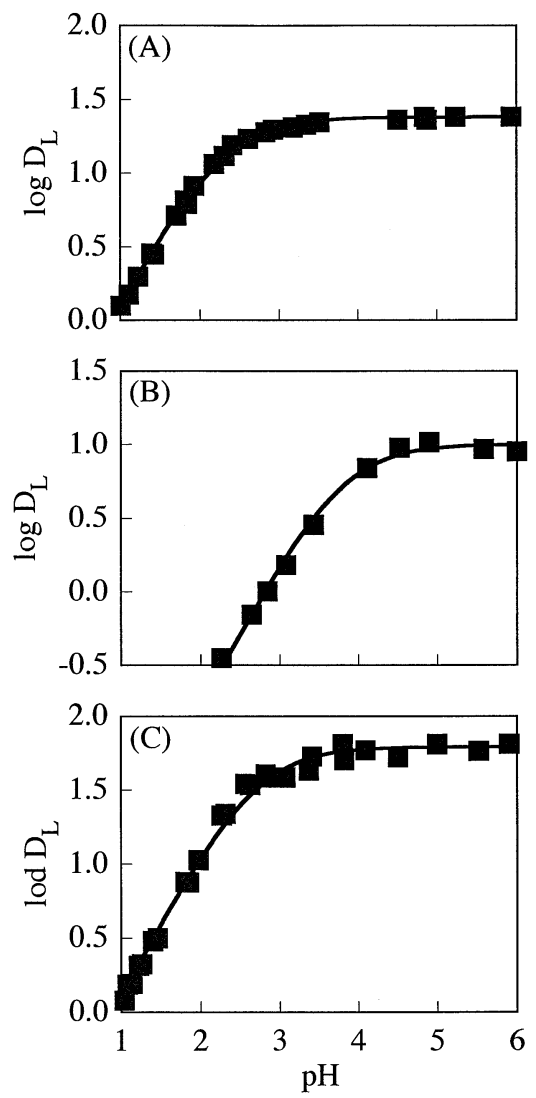

Fig. 2 Plots of the logarithmic distribution ratios $\left(\log D_{\mathrm{L}}\right)$ of BQIE (A), BPMP (B) and BQMP (C) into nitrobenzene as a function of the aqueous phase $\mathrm{pH}$ equilibrated with the organic phase. Initial concentration of a ligand was $1 \times 10^{-4} \mathrm{~mol} \mathrm{dm}^{-3}$. The solid curve was obtained by the non-linear least square fit.

\section{Distribution of the metal cations}

The distribution of metal cations was studied as follows: in a centrifuge tube, an aliquot of nitrobenzene $\left(5 \mathrm{~cm}^{3}\right)$ containing 1 $\times 10^{-3} \mathrm{~mol} \mathrm{dm}^{-3}$ of a ligand and an equal volume of an aqueous phase containing $1 \times 10^{-5}-1 \times 10^{-4} \mathrm{~mol} \mathrm{dm}^{-3}$ of $\mathrm{M}^{2+}(\mathrm{M}=\mathrm{Mn}$, $\mathrm{Co}, \mathrm{Ni}, \mathrm{Cu}, \mathrm{Zn}, \mathrm{Cd}$ or $\mathrm{Pb}$ ), $1 \times 10^{-3} \mathrm{~mol} \mathrm{dm}^{-3}$ of sodium picrate (NaPic) as ion-pair reagent, $1 \times 10^{-1} \mathrm{~mol} \mathrm{dm}^{-3}$ of potassium nitrate and $1 \times 10^{-2} \mathrm{~mol} \mathrm{dm}^{-3}$ of buffer (chloroacetic acid, acetic acid or MES) that had no influence on the extraction, were shaken at $25 \pm 1^{\circ} \mathrm{C}$ for $1 \mathrm{~h}$ (all of the extraction was equilibrated within $30 \mathrm{~min}$ ). After the two phases were separated by centrifugation, the $\mathrm{pH}$ and the metal concentration in the aqueous phase were determined and the measured $\mathrm{pH}$ was used as the equilibrated $\mathrm{pH}$. The metal concentration in the organic phase was determined after back-extraction with $1 \mathrm{~mol} \mathrm{dm}^{-3}$ nitric acid.

\section{Results and Discussion}

Acid dissociation and distribution of ligands

BQIE, BPMP and BQMP, as well as BPIE, have four nitrogen atoms which can be protonated. Therefore, the following acid dissociation equilibria in aqueous phase must be considered:

$$
\begin{aligned}
& \mathrm{H}_{5-i} \mathrm{~L}^{(5-i)+} \rightleftharpoons \mathrm{H}_{4-i} \mathrm{~L}^{(4-i)+}+\mathrm{H}^{+}(1 \leq i \leq 4) \\
& K_{\mathrm{ai}}=\left[\mathrm{H}^{+}\right]\left[\mathrm{H}_{4-i} \mathrm{~L}^{(4-i)+}\right] /\left[\mathrm{H}_{5-i} \mathrm{~L}^{(5-i)+}\right]
\end{aligned}
$$



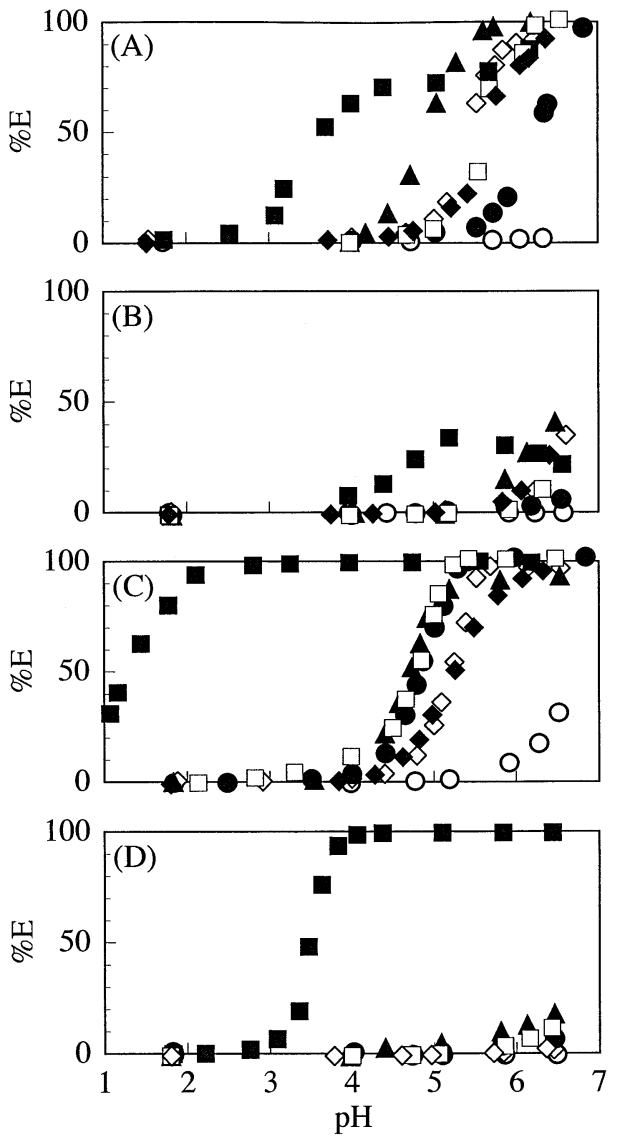

Fig. 3 Plots of the extracted ratios $(\% E)$ for some divalent metal cations as a function of the aqueous phase $\mathrm{pH}$ equilibrated with nitrobenzene phase in BPIE-NaPic ${ }^{7}$ (A), BQIE-NaPic (B), BPMP$\mathrm{NaPic}^{8}(\mathrm{C})$ and $\mathrm{BQMP}-\mathrm{NaPic}(\mathrm{D})$ systems. Initial concentrations were $1 \times 10^{-3} \mathrm{M}$ for BPIE, BQIE, BPMP or BQMP in nitrobenzene and $1 \times 10^{-3} \mathrm{M} \mathrm{NaPic}$ in aqueous phase. $\mathrm{O}, \mathrm{Mn}^{2+} ; \diamond, \mathrm{Co}^{2+} ; \mathbf{\Lambda}, \mathrm{Ni}^{2+}$ •, $\mathrm{Cu}^{2+} ; \bullet, \mathrm{Zn}^{2+} ; \square, \mathrm{Cd}^{2+} ; \bullet, \mathrm{Pb}^{2+}$.

where $\mathrm{L}$ and $K_{\mathrm{a} i}$ designate a ligand and $i$-th acid dissociation constant for $\mathrm{L}$, respectively. In this case, the distribution ratio of $\mathrm{L}\left(D_{\mathrm{L}}\right)$ between nitrobenzene and aqueous phases at fixed $\mathrm{pH}$ is shown as follows:

$$
\begin{aligned}
D_{\mathrm{L}}= & {[\mathrm{L}]_{\mathrm{o}} /\left(\left[\mathrm{H}_{4} \mathrm{~L}^{4+}\right]+\left[\mathrm{H}_{3} \mathrm{~L}^{3+}\right]+\left[\mathrm{H}_{2} \mathrm{~L}^{2+}\right]+\left[\mathrm{HL}^{+}\right]+[\mathrm{L}]\right) } \\
= & K_{\mathrm{D}} /\left(\left[\mathrm{H}^{+}\right]^{4} / K_{\mathrm{a} 1} K_{\mathrm{a} 2} K_{\mathrm{a} 3} K_{\mathrm{a} 4}+\left[\mathrm{H}^{+}\right]^{3} / K_{\mathrm{a} 2} K_{\mathrm{a} 3} K_{\mathrm{a} 4}\right. \\
& \left.+\left[\mathrm{H}^{+}\right]^{2} / K_{\mathrm{a} 3} K_{\mathrm{a} 4}+\left[\mathrm{H}^{+}\right] / K_{\mathrm{a} 4}+1\right)
\end{aligned}
$$

where subscript o means the organic phase and $K_{\mathrm{D}}$ designates the distribution constant of $\mathrm{L}$ defined as follows:

$$
K_{\mathrm{D}}=[\mathrm{L}]_{\mathrm{o}} /[\mathrm{L}]
$$

Therefore, the non-linear least-squares fitting method is applicable to a $\log D_{\mathrm{L}} v s$. $\mathrm{pH}$ plot for the determination of $\mathrm{p} K_{\mathrm{a} i}$ and $\log K_{\mathrm{D}}$. Figure 2 shows the plot and the fitting curve. Since $\mathrm{p} K_{\mathrm{a} 1}, \mathrm{p} K_{\mathrm{a} 2}$ and $\mathrm{p} K_{\mathrm{a} 3}$ values were very low, these values hardly affected the distribution of $\mathrm{L}$. The obtained values of $\mathrm{p} K_{\mathrm{a} 4}$ and $\log K_{\mathrm{D}}$ were 2.26 and 1.38 for BQIE, 3.77 and 1.00 for BPMP and 2.68 and 1.79 for BQMP.

The obtained $\mathrm{p} K_{\mathrm{a} 4}$ value of BPMP is the almost same as that of BPIE ( $\left.\mathrm{p} K_{\mathrm{a} 4}=3.82\right),{ }^{7}$ and those of BQIE and BQMP are lower than those of BPIE and BPMP, respectively. Namely, the basicity of imine-N atom in BQIE and BQMP was decreased
Table 1 The obtained half-extraction $\mathrm{pH}\left(\mathrm{pH}_{1 / 2}\right)$ values on $\mathrm{L}$ NaPic systems $\left(25 \pm 1^{\circ} \mathrm{C}\right)$

\begin{tabular}{ccccc}
\hline Cation & $\mathrm{L}=\mathrm{BPIE}^{3}$ & $\mathrm{~L}=\mathrm{BQIE}$ & $\mathrm{L}=\mathrm{BPMP}^{8}$ & $\mathrm{~L}=\mathrm{BQMP}$ \\
\hline $\mathrm{Mn}^{2+}$ & n.e. $^{\mathrm{a}}$ & n.e. $^{\mathrm{a}}$ & $6.8^{\mathrm{b}}$ & n.e. $^{\mathrm{a}}$ \\
$\mathrm{C}^{2+}$ & 5.42 & $6.8^{\mathrm{b}}$ & 5.21 & n.e. \\
$\mathrm{Ni}^{\mathrm{a}}$ & 4.91 & $6.7^{\mathrm{b}}$ & 4.71 & n.e. \\
$\mathrm{Cu}^{2+}$ & 3.64 & $<50 \% E^{\mathrm{c}}$ & 1.28 & 3.48 \\
$\mathrm{Zn}^{2+}$ & 6.25 & n.e. $^{\mathrm{a}}$ & 4.83 & n.e. \\
$\mathrm{Cd}^{2+}$ & 5.62 & n.e. $^{\mathrm{a}}$ & 4.80 & n.e. $^{\mathrm{a}}$ \\
$\mathrm{Pb}^{2+}$ & 5.64 & n.e. $^{\mathrm{a}}$ & 5.25 & n.e. \\
\hline
\end{tabular}

a. Not extracted.

b. Extrapolated value.

c. Less than $50 \%$ extraction.

compared with the basicity in their 2-pyridyl analogues. This result suggests lower complexation abilities of BQIE and BQMP than those of BPIE and BPMP. In addition, the higher $\log K_{\mathrm{D}}$ values for BQIE and BQMP compared with those of BPIE $\left(\log K_{\mathrm{D}}=0.98\right)^{7}$ and BPMP are obviously caused by their high hydrophobicity based on 2-quinolyl groups.

\section{Distribution of the metal cations}

The extracted ratio $(\% E)$ for some divalent metal cations into nitrobenzene with BPIE- ${ }^{7}$ BQIE-, BPMP- ${ }^{8}$ and BQMP-NaPic systems is plotted as a function of the equilibrated $\mathrm{pH}$ in Fig. 3, and half-extraction $\mathrm{pH}$ values $\left(\mathrm{pH}_{1 / 2}\right)$ are given in Table 1 . The $\% E$ became constant with shaking for more than $30 \mathrm{~min}$. The extraction curves were not changed with changing the initial concentration of $\mathrm{M}^{2+}$. Thus, it was confirmed that the dimerization and the dissociation of extracted mononuclear complex and the formation of polynuclear complex are negligible in these systems, as reported previously. ${ }^{7}$

As shown in Fig. 3, the apparent extractability of BPMP$\mathrm{NaPic}$ system is higher than that of BPIE-NaPic system. Furthermore, many metal cations such as $\mathrm{Cd}^{2+}, \mathrm{Ni}^{2+}, \mathrm{Zn}^{2+}, \mathrm{Co}^{2+}$ and $\mathrm{Pb}^{2+}$ showed extraction curves similar to each other. On the contrary, BQIE- and BQMP-NaPic systems showed remarkably low extractability. In BQMP-NaPic system, particularly, only $\mathrm{Cu}^{2+}$ can be extracted quantitatively.

\section{Extracted species}

The extraction equilibrium in BQIE, BPMP and BQMP systems seems to be same as that in BPIE system. ${ }^{7}$ When the dissociation of extracted species is negligible, the extraction equilibrium of $\mathrm{M}^{2+}$ in $\mathrm{L}-\mathrm{NaPic}$ system can be described as follows:

$$
\begin{aligned}
& \mathrm{M}^{2+}+n \mathrm{~L}_{\mathrm{o}}+2 \mathrm{Pic}^{-} \rightleftharpoons \mathrm{ML}_{n}^{2+} \cdot 2 \mathrm{Pic}_{\mathrm{o}}^{-} \\
& K_{\mathrm{ex}}=\left[\mathrm{ML}_{n}^{2+} \cdot 2 \mathrm{Pic}^{-}\right]_{\mathrm{o}} /\left[\mathrm{M}^{2+}\right][\mathrm{L}]_{\mathrm{o}}{ }^{n}\left[\mathrm{Pic}^{-}\right]^{2}
\end{aligned}
$$

In this case, the distribution ratio of $\mathrm{M}^{2+}(D)$ is described as follows:

$$
\begin{aligned}
D & =\left[\mathrm{ML}_{n}{ }^{2+} \cdot 2 \mathrm{Pic}^{-}\right]_{\mathrm{o}} /\left[\mathrm{M}^{2+}\right] \\
& =K_{\mathrm{ex}}[\mathrm{L}]_{0}{ }^{n}\left[\mathrm{Pic}^{-}\right]^{2}
\end{aligned}
$$

$\log D=\log K_{\text {ex }}+n \log [\mathrm{L}]_{\mathrm{o}}+2 \log \left[\mathrm{Pic}^{-}\right]$

$\approx \log K_{\mathrm{ex}}+n \log C_{0}(\mathrm{~L})+2 \log C(\mathrm{NaPic})$

$-n \log \left\{1+\left(1+\left[\mathrm{H}^{+}\right] / K_{\mathrm{a} 4}+\left[\mathrm{H}^{+}\right]^{2} / K_{\mathrm{a} 3} K_{\mathrm{a} 4}\right.\right.$ $\left.\left.+\left[\mathrm{H}^{+}\right]^{3} / K_{\mathrm{a} 2} K_{\mathrm{a} 3} K_{\mathrm{a} 4}+\left[\mathrm{H}^{+}\right]^{4} / K_{\mathrm{a} 1} K_{\mathrm{a} 2} K_{\mathrm{a} 3} K_{\mathrm{a} 4}\right) / K_{\mathrm{D}}\right\}$

$\approx \log K_{\mathrm{ex}}+n \log C_{0}(\mathrm{~L})+2 \log C(\mathrm{NaPic})$ $-n \log \left\{1+\left(1+\left[\mathrm{H}^{+}\right] / K_{\mathrm{a} 4}\right) / K_{\mathrm{D}}\right\}$ 
Table 2 The determined $n$ values in extracted $\mathrm{ML}_{n}{ }^{2+} \cdot 2 \mathrm{Pic}^{-}$species and extraction constants $\left(K_{\mathrm{ex}}\right)$ on L-NaPic systems $\left(25 \pm 1^{\circ} \mathrm{C}\right)$

\begin{tabular}{|c|c|c|c|c|c|c|c|c|}
\hline \multirow{2}{*}{ Cation } & \multicolumn{2}{|c|}{$\mathrm{L}=\mathrm{BPIE}^{7}$} & \multicolumn{2}{|c|}{$\mathrm{L}=\mathrm{BQIE}$} & \multicolumn{2}{|c|}{$\mathrm{L}=\mathrm{BPMP}$} & \multicolumn{2}{|c|}{$\mathrm{L}=\mathrm{BQMP}$} \\
\hline & Species & $\log K_{\text {ex }}$ & Species & $\log K_{\text {ex }}$ & Species $^{8}$ & $\log K_{\mathrm{ex}}$ & Species & $\log K_{\mathrm{ex}}$ \\
\hline $\mathrm{Co}^{2+}$ & $\mathrm{CoL}_{3}^{2+} \cdot 2 \mathrm{Pic}^{-}$ & $15.2 \pm 0.3$ & $\mathrm{CoL}_{2}{ }^{2+} \cdot 2 \mathrm{Pic}^{-}$ & $11.1 \pm 0.1$ & $\mathrm{CoL}_{3}{ }^{2+} \cdot 2 \mathrm{Pic}^{-}$ & $15.7 \pm 0.1$ & n.e. ${ }^{a}$ & n.e. ${ }^{a}$ \\
\hline $\mathrm{Ni}^{2+}$ & $\mathrm{NiL}_{3}^{2+} \cdot 2 \mathrm{Pic}^{-}$ & $15.3 \pm 0.1$ & $\mathrm{NiL}_{2}^{2+} \cdot 2 \mathrm{Pic}^{-}$ & $11.7 \pm 0.1$ & $\mathrm{NiL}_{2}^{2+} \cdot 2 \mathrm{Pic}^{-}$ & $12.0 \pm 0.1$ & n.e. ${ }^{a}$ & n.e. ${ }^{a}$ \\
\hline $\mathrm{Cu}^{2+}$ & $\mathrm{CuL}_{2}^{2+} \cdot 2 \mathrm{Pic}^{-}$ & $12.4 \pm 0.4$ & $\mathrm{CuL}_{2}^{2+} \cdot 2 \mathrm{Pic}^{-}$ & $11.8 \pm 0.2$ & $\mathrm{CuL}^{2+} \cdot 2 \mathrm{Pic}^{-}$ & $10.3 \pm 0.2$ & $\mathrm{CuL}_{2}^{2+} \cdot 2 \mathrm{Pic}^{-}$ & $12.3 \pm 0.2$ \\
\hline $\mathrm{Zn}^{2+}$ & $\mathrm{ZnL}_{3}^{2+} \cdot 2 \mathrm{Pic}^{-}$ & $14.4 \pm 0.2$ & n.e. ${ }^{\mathrm{a}}$ & n.e. ${ }^{a}$ & $\mathrm{ZnL}_{2}^{2+} \cdot 2 \mathrm{Pic}^{-}$ & $15.3 \pm 0.3$ & n.e. ${ }^{a}$ & n.e. ${ }^{a}$ \\
\hline $\mathrm{Cd}^{2+}$ & $\mathrm{CdL}_{3}^{2+} \cdot 2 \mathrm{Pic}^{-}$ & $14.9 \pm 0.2$ & n.e. ${ }^{a}$ & n.e. ${ }^{a}$ & $\mathrm{CdL}_{2}{ }^{2+} \cdot 2 \mathrm{Pic}^{-}$ & $12.4 \pm 0.2$ & n.e. ${ }^{a}$ & n.e. $^{\mathrm{a}}$ \\
\hline $\mathrm{Pb}^{2+}$ & $\mathrm{PbL}_{3}^{2+} \cdot 2 \mathrm{Pic}^{-}$ & $14.7 \pm 0.2$ & n.e. ${ }^{a}$ & n.e. ${ }^{a}$ & $\mathrm{PbL}_{2}^{2+} \cdot 2 \mathrm{Pic}^{-}$ & $12.3 \pm 0.1$ & n.e. ${ }^{a}$ & n.e. ${ }^{a}$ \\
\hline
\end{tabular}

a. Not extracted.
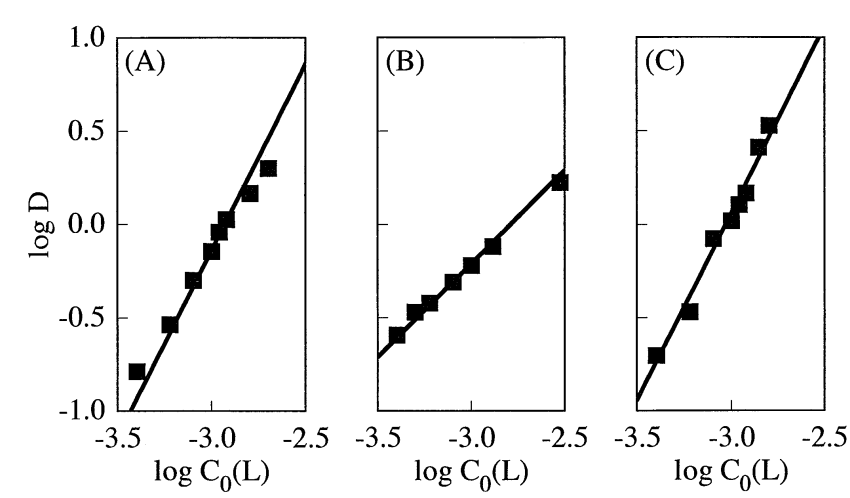

Fig. 4 Plots of the logarithmic distribution ratios $(\log D)$ for $\mathrm{Cu}^{2+}$ into nitrobenzene with BQIE-NaPic (A), BPMP-NaPic (B) and BQMP-NaPic (C) systems as a function of the logarithmic initial concentration of a ligand in nitrobenzene phase. Initial concentration of $\mathrm{NaPic}$ in aqueous phase was $1 \times 10^{-3} \mathrm{M}$. Aqueous phase $\mathrm{pH}$ was 5.1 (A), 1.3 (B) and 3.5 (C). The solid line, of which the slope is 1 (B) or $2(\mathrm{~A}, \mathrm{C})$, was obtained by the least square fit.

where $C_{0}(\mathrm{~L})$ and $C(\mathrm{NaPic})$ are the initial concentration of $\mathrm{L}$ in organic phase and that of NaPic in aqueous phase, respectively. Therefore, the plot of $\log D v s . \log C_{0}(\mathrm{~L})$ at fixed $\mathrm{pH}$ and $C$ (NaPic) is expected to give a straight line, and $n$ can be determined from the slope of the line.

Figure 4 shows examples of the plot of $\log D v s . \log C_{0}(\mathrm{~L})$. The determined composition of the extracted species (obtained $n$ values) and $\log K_{\text {ex }}$ values are shown in Table 2, with those in BPIE-NaPic system. ${ }^{7}$ Only in the case of $\mathrm{Cu}^{2+}$ in BPMP-NaPic system, $n=1$ was obtained. This specific result suggests that BPMP acts as normal pyridine- $\mathrm{N}$-imine- $\mathrm{N}$-imine- $\mathrm{N}$-pyridine- $\mathrm{N}$ quadridentate ligand exceptionally in the extraction of $\mathrm{Cu}^{2+} .8$ In BQMP-NaPic system, to the contrary, $n=2$ was obtained in the case of $\mathrm{Cu}^{2+}$. This result is discussed below.

\section{Structural control of ligands}

Effect of pendant arms. As shown in Fig. 3, the extractability of BQIE was decreased compared with that of BPIE. Since polarity of 2-quinolyl groups is lower than that of 2-pyridyl groups, it is considered that relatively low lipophilicity of BQIE to nitrobenzene resulted in its low extractability. This hypothesis can be supported by the fact that almost no metal cations were extracted by using ligand having non-polar phenyl groups as pendant arms (the data are not shown here). In addition, extraction selectivity of BQIE-NaPic system was very similar to that of BPIE-NaPic system. Namely, these results suggested that modification of the pendant arms does not bring on any change in extraction selectivity but only in extractability, which originates from the difference of lipophilicity to nitrobenzene.

Effect of distance between two imine- $N$ donor atoms. As shown in Fig. 3, it was found that quantitative extraction of metal cations except for $\mathrm{Mn}^{2+}$ was achieved in BPMP-NaPic system. It was considered that the trimethylene backbone is a suitable

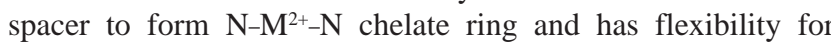
fitting to any metal cations on the complexation. ${ }^{8}$ Furthermore, as shown in Table 1, the $\mathrm{pH}_{1 / 2}$ value of $\mathrm{Cu}^{2+}$ was far from the $\mathrm{pH}_{1 / 2}$ values of the other metals $\left(\mathrm{pH}_{1 / 2}-\mathrm{pH}_{1 / 2}\left(\mathrm{Cu}^{2+}\right)>3.5\right)$. The distance between the donors in BPMP is suitable for selective extraction of $\mathrm{Cu}^{2+}$ from the other cations. In addition, the $1: 1$ complex with $\mathrm{Cu}^{2+}$ in BPMP-NaPic system seems to be more stable than 1:2 complex.

BQMP is another analogue of BPIE having both 2-quinolyl pendant arms and trimethylene backbone structure; BQMP is expected to have not only similar extraction selectivity to BPMP but also lower extractability than BPMP. In BQMPNaPic system as shown in Fig. 3, only $\mathrm{Cu}^{2+}$ was extracted selectively. This result corresponds to the expectation, provided that $n=2$ was obtained in the extraction of $\mathrm{Cu}^{2+}$. In BPMPNaPic system, as mentioned above, 1:1 complex with $\mathrm{Cu}^{2+}$ is more stable than 1:2 in nitrobenzene. In BQMP-NaPic system, on the contrary, the stability order seems to be reversed because of the relatively low lipophilicity of the 2-quinolyl pendant arms. In addition, the bulky 2-quinolyl pendant arms seem to result in steric inhibition on the 1:1 complex formation to some extent. Nevertheless, the high selectivity for $\mathrm{Cu}^{2+}$ was maintained, and mutual separation for $\mathrm{Cu}^{2+}$ from divalent metal cations can be achieved in the BQMP-NaPic system over a wide $\mathrm{pH}$ region.

\section{Acknowledgements}

This study was financially supported in part by the Sasagawa Scientific Research Grant No. 13-128 from the Japan Science Society (S. O.) and Grant-in-Aid for Scientific Research No. 13740420 from The Ministry of Education, Culture, Sports, Science and Technology, Japan (N. H.).

\section{References}

1. T. Honjo, H. Imaizumi, K. Ueda, K. Sato, K. Sawada, Y. Sohrin, S. Taguchi, Y. Nagaosa, K. Hasegawa, N. Hirayama, J. Miura, A. Yamada, M. Yamamoto, and T. Yoshikuni, "Basic Analytical Chemistry”, 1998, Kagaku Dojin, Kyoto.

2. M. Tanaka and H. Akaiwa, "Solvent Extraction Chemistry”, 2000, Shokabo, Tokyo. 
3. D. H. Busch and J. C. Bailar, J. Am. Chem. Soc., 1956, 78, 1137.

4. R. Föhring and H. Specker, Fresenius Z. Anal. Chem., 1973, 264, 378 .

5. S. Gourbatsis, J. C. Plakatouras, V. Nastopoulos, C. J. Cardin, and N. Hadjiliadis, Inorg. Chem. Commun., 1999, 2,468 .
6. M. Louloudi, V. Nastopoulos, S. Gourbatsis, S. P. Perlepes, and N. Hadjiliadis, Inorg. Chem. Commun., 1999, $2,479$.

7. S. Oshima, N. Hirayama, K. Kubono, H. Kokusen, and T. Honjo, Anal. Chim. Acta, 2001, 441, 155.

8. S. Oshima, N. Hirayama, K. Kubono, H. Kokusen, and T. Honjo, Anal. Sci., 2001, 17 (Supplement), i1287. 